\title{
Renal Sympathetic Denervation Therapy for Treatment of Resistant Hypertension
}

\section{Wilbert S. Aronow*}

Cardiology Division, Department of Medicine, New York Medical College/Westchester Medical Center, Valhalla, New York, USA

Hypertension is a major risk factor for cardiovascular disease [1]. Hypertension is present in $69 \%$ of patients with a first myocardial infarction [2], in $77 \%$ of patients with a first stroke [2], in $74 \%$ of patients with congestive heart failure [2], and in $60 \%$ of patients with peripheral arterial disease [3]. Hypertension is also a major risk factor for a dissecting aortic aneurysm, sudden cardiac death, angina pectoris, atrial fibrillation, diabetes mellitus, the metabolic syndrome, chronic kidney disease, thoracic and abdominal aortic aneurysms, left ventricular hypertrophy, vascular dementia, Alzheimer's disease, and ophthalmologic disorders [1].

A statement from the American Heart Association diagnosed resistant hypertension as a blood pressure remaining above goal despite the use of 3 optimally dosed antihypertensive drugs from different classes, with one of the drugs being a diuretic [4]. The National Institute for Health and Clinical Excellence guideline suggests that the 3 drugs should be an angiotensin-converting enzyme inhibitor or angiotensin blocker plus a calcium channel blocker plus a thiazide-type diuretic [5].

Before a patient is considered to have resistant hypertension, pseudo-resistant hypertension and white coat-resistant hypertension must be excluded $[5,6]$. Poor patient compliance, inadequate doses of antihypertensive drugs, inadequate choice of combinations of antihypertensive drugs, poor office blood pressure measurement technique, and having to pay for costs of drugs are factors associated with resistant hypertension $[1,7]$.

Factors contributing to resistant hypertension include obesity, excess dietary sodium, excess alcohol intake, use of cocaine, amphetamines, non-steroidal anti-inflammatory drugs, contraceptive hormones, adrenal steroid hormones, sympathomimetic drugs (nasal decongestants and diet pills), erythropoietin, licorice, herbal supplements such as ephedra, progressive renal insufficiency, and inadequate diuretic therapy [5]. Secondary causes of resistant hypertension include primary hyperaldosteronism, renal artery stenosis, renal parenchymal disease, obstructive sleep apnea, coarctation of the aorta, Cushing's syndrome, pheochromocytoma, hyperthyroidism, hypothyroidism, and intracranial tumors $[5,8]$.

Patients with resistant hypertension have an increased incidence of cardiovascular events $[9,10]$. Therefore, more effort is indicated to improve clinical outcomes in these patients.

Some data support the use of spironolactone as a fourth drug in the treatment of resistant hypertension if the serum potassium level is $\leq 4.5 \mathrm{mmol} / \mathrm{L}[5,11]$. New drugs and device therapy with percutaneous transluminal radiofrequency sympathetic denervation of the renal arteries and carotid baroreflex activation are currently under investigation for treatment of resistant hypertension [12].

Catheter-based percutaneous renal denervation therapy to ablate the sympathetic fibers along the renal artery has generated great enthusiasm among physicians treating resistant hypertension [13]. At 24-month follow-up after catheter-based renal sympathetic denervation of 153 patients with resistant hypertension, postprocedure office blood pressure was $32 / 14 \mathrm{~mm} \mathrm{Hg}$ lower without significant adverse events in the Symplicity HTN-1 study [14]. At 12-month follow-up after catheterbased renal sympathetic denervation of 49 patients with resistant hypertension in the initial renal denervation group, postprocedure office systolic blood pressure was $28.1 \mathrm{~mm} \mathrm{Hg}$ lower in the Symplicity HTN-2 study [15]. At 6-month follow-up after catheter-based renal sympathetic denervation of 35 patients with resistant hypertension in the crosover renal denervation group, postprocedure office systolic blood pressure was $23.7 \mathrm{~mm} \mathrm{Hg}$ lower in the Symplicity HTN-2 study [15]. In the crossover group, 1 patient had renal artery stenting for renal artery dissection, and 1 hypotensive episode resolved with medication adjustment [15].

A meta-analysis was performed of 12 studies with a total of 561 patients investigating use of catheter-based renal sympathetic denervation for treating patients with resistant hypertension [13]. These studies included 2 randomized controlled trials with 133 patients, 1 observational study with a control group with 50 patients, and 9 observational studies without a control group with 396 patients. At a median follow-up of 6 months, renal sympathetic denervation caused a reduction of blood pressure of 28.9/11.0 $\mathrm{mm} \mathrm{Hg}$ [13].

The European Society of Hypertension position paper summarizes current evidence, unmet needs, and practical recommendations on use of renal sympathetic denervation to treat resistant hypertension in hypertension excellence centers [16]. This therapy is currently approved for treatment of resistant hypertension in Europe and in Canada [13].

Despite these results, this author has stated at medical meetings that renal sympathetic denervation for treatment of resistant hypertension is a very exciting development but needs long-term cardiovascular outcome data which are not available and which needs a large-scale prospective study of patients with resistant hypertension randomized to this interventional procedureversus a sham procedure control arm. Long-term cardiovascular outcome data are not yet available. However, the Symplicity HTN-3 study has just been reported in the press to state that renal sympathetic denervation using a Medtronic Symplicity catheter system to treat resistant hypertension was no better than a sham-control arm in reducing office systolic blood pressure at 6 months [17].

The Symplicity HTN-3 study randomized 535 patients with treatment resistant hypertension to renal sympathetic denervation using a Medtronic Symplicity catheter system or to a sham-control

${ }^{*}$ Corresponding author: Wilbert S. Aronow, MD, FACC, FAHA, Cardiology Division, New York Medical College, Macy Pavilion, Room 138, Valhalla, NY 10595 USA, Tel: (914) 493-5311; Fax: (914)-235-6274, E-mail: wsaronow@aol.com

Received January 11, 2014; Accepted January 14, 2014; Published January 16 2014

Citation: Aronow WS (2014) Renal Sympathetic Denervation Therapy for Treatment of Resistant Hypertension. J Hypertens 3: e111. doi:10.4172/2167 1095.1000e111

Copyright: (c) 2014 Aronow WS. This is an open-access article distributed under the terms of the Creative Commons Attribution License, which permits unrestricted use, distribution, and reproduction in any medium, provided the original author and source are credited. 
Citation: Aronow WS (2014) Renal Sympathetic Denervation Therapy for Treatment of Resistant Hypertension. J Hypertens 3: e111. doi:10.4172/21671095.1000e111

arm. At 6-month follow-up, the primary end point of the change in office systolic blood pressure at 6 months was not significantly different between both treated groups [17]. This study is the largest and best study investigating the efficacy of renal sympathetic denervation in treating resistant hypertension and the only study to use an appropriate shamcontrol arm. I commend Medtronics for conducting this study. This study is another study showing why appropriate controls are needed in clinical studies to avoid the powerful placebo effect. Deepak Bhatt, $\mathrm{MD}$, one of the co-principal investigators of this trial, stated in a press interview on January 9, 2014 that the data from this trial are currently being analyzed and will be submitted for peer review, presentation, and publication.

\section{References}

1. Aronow WS, Fleg JL, Pepine CJ, Artinian NT, Bakris G, et al. (2011) ACCF/AHA 2011 expert consensus document on hypertension in the elderly: a report of the American College of Cardiology Foundation Task Force on Clinical Expert Consensus Documents. Circulation 123: 2434-2506.

2. Lloyd-Jones $D$, Adams $R$, Carnethon M, De Simone G, Ferguson TB, et al. (2009) Heart disease and stroke statistics--2009 update: a report from the American Heart Association Statistics Committee and Stroke Statistics Subcommittee. Circulation 119: e21-181.

3. Aronow WS, Ahmed MI, Ekundayo OJ, Allman RM, Ahmed A (2009) A propensity-matched study of the association of peripheral arterial disease with cardiovascular outcomes in community-dwelling older adults. Am J Cardiol 103: 130-135.

4. Calhoun DA, Jones D, Textor S, Goff DC, Murphy TP, et al. (2008) Resistant hypertension: diagnosis, evaluation, and treatment: a scientific statement from the American Heart Association Professional Education Committee of the Council for High Blood Pressure Research. Circulation 117: e510-526.

5. Myat A, Redwood SR, Qureshi AC, Spertus JA, Williams B (2012) Resistan hypertension. BMJ 345: e7473.

6. Pimenta E, Calhoun DA (2012) Resistant hypertension: incidence, prevalence, and prognosis. Circulation 125: 1594-1596.
7. Gandelman G, Aronow WS, Varma R (2004) Prevalence of adequate blood pressure control in self-pay or Medicare patients versus Medicaid or private insurance patients with systemic hypertension followed in a university cardiology or general medicine clinic. Am J Cardiol 94: 815-816.

8. Chiong JR, Aronow WS, Khan IA, Nair CK, Vijayaraghavan K, et al. (2008) Secondary hypertension: current diagnosis and treatment. Int J Cardiol 124: 6-21.

9. Kumbhani DJ, Steg PG, Cannon CP, Eagle KA, Smith SC Jr, et al. (2013) Resistant hypertension: a frequent and ominous finding among hypertensive patients with atherothrombosis. Eur Heart J 34: 1204-1214.

10. Daugherty SL, Powers JD, Magid DJ, Tavel HM, Masoudi FA, et al. (2012) Incidence and prognosis of resistant hypertension in hypertensive patients Circulation 125: 1635-1642.

11. Chapman N, Dobson J, Wilson S, Dahlöf B, Sever PS, et al. (2007) Effect of spironolactone on blood pressure in subjects with resistant hypertension. Hypertension 49: 839-845.

12. Laurent S, Schlaich M, Esler M (2012) New drugs, procedures, and devices for hypertension. Lancet 380: 591-600.

13. Davis MI, Filion KB, Zhang D, Eisenberg MJ, Afilalo J, et al. (2013) Effectiveness of renal denervation therapy for resistant hypertension: a systematic review and meta-analysis. J Am CollCardiol 62: 231-241.

14. Symplicity HTN-1 Investigators (2011) Catheter-based renal sympathetic denervation for resistant hypertension: durability of blood pressure reduction out to 24 months. Hypertension 57: 911-917.

15. Esler MD, Krum H, Schlaich M, Schmieder RE, Böhm M, et al. (2012) Renal sympathetic denervation for treatment of drug-resistant hypertension: one-year results from the Symplicity HTN-2 randomized, controlled trial. Circulation 126 : 2976-2982.

16. Schmieder RE, Redon J, Grassi G, Kjeldsen SE, Mancia G, et al. (2012) ESH position paper: renal denervation - an interventional therapy of resistant hypertension. J Hypertens 30: 837-841.

17. Medtronic press statement. January 09, 2014 